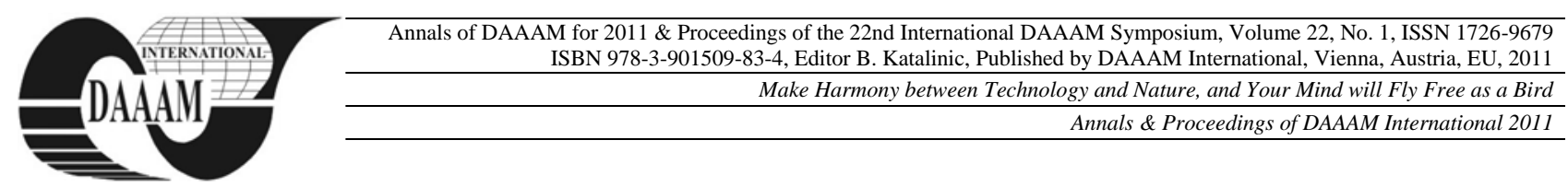

\title{
OPTIMIZATION OF MATERIAL FLOW IN ENGINEERING COMPANY
}

\author{
BELUSKY, M[artin]; HODULIK, M[arian] \& VIDOVA, H[elena]
}

\begin{abstract}
The aim of work is creating algorithm, based on minimizing material flow, which is able to deploy workstations in optimal mutual positions. In first part of the work I describe basic methods for space deployment workstations. In second part I suggest my own problem solution through application created in program Lazarus. In last part of work I am concerned of valorization my achieved results.

Key words: triangle method, material flow, optimization
\end{abstract}

\section{INTRODUCTION}

One of the main conditions of the production process in terms of its functions, and thus the organization and production management is to ensure continuity and acceleration of movement of work objects. Movement of working manufacturing process objects is called material flow of the product. Material flow is the main criterion for the spatial arrangement of production units, i.e. layout of buildings, roads, machinery and equipment, offices, workshops and warehouses.

\section{ALLOCATION MANAGEMENT}

Allocation of production management is dealing with the spatial distribution of objects and inside objects the allocation of workplaces so, that production could be flexibly adapted to commercial innovation and change. The task is difficult, because the spatial realities of production are still more or less predetermined and stable. Thus, a search for nontraditional allocation solution is required. The focus should move to a larger variation in the design and construction of manufactory, and no additional space for adjustments. (Leščišin \& Stern, 1998)

The principal object of the allocation process is workplaces. Workplace is defined as relatively limited production space in which the work operation is carried out. Its basic elements are the workforce, the equipment and the work object. (Leščišin \& Stern, 1998)

\section{ALLOCATION METHODS}

First field of methods are graphic methods. The basis of graphic methods is graphical models. Graphical representation of various phenomena and processes has many advantages. The graph shows the phenomena and processes in much interpretative, concentrated, and the exact form of rationale. Charts can be used for analysis of the current process and its improvement.

In rationalizing production, the most commonly used graphical methods are:

- schemes: progression charts and diagrams, diagrams of complex activities,

- chronographic: schedules, network diagrams, Gantt charts,

- topographic: Sankey diagram, method of coordinates, triangular method,
- other diagrams.

(Rybanský \& Drahňovský, 2009)

Triangular method allows not only illustrating the movement of production in space, but also directly addressing the spatial location of objects and places of work to come down to the optimum. Case of a problem is used geometric theorem that the two objects, there is only a short connection, because objects with the largest volume of bilateral operations are located as close to each other. An essential element of the solution is a triangle, where the objects with the largest transport relations are placed. (Rybanský \& Drahňovský, 2009)

Next field of methods are mathematical methods. The basis of mathematical methods is mathematical models based. These models are based on a high abstraction, and are most useful in all models. These methods, along with some other methods, are usually called as methods of operational research or operational analysis. This includes e.g.: mathematical programming, a method of balancing production, the method of deployment facilities (CRAFT), queuing theory, the problem of the sequence of work (sequence problem) and so on. Static methods, as next field of allocation methods, belong to the basic tool used in virtually all phases of rationalization of production. These methods allow quantifying the phenomena and processes, thus creating conditions for their improvement. Of these methods can be used in particular: a selection method, correlation and regression analysis, analysis of variance and statistical dynamics. The other methods are for example system analysis, value analysis, decision analysis, surface and spatial models and many others. (Rybanský \& Drahňovský, 2009)

\section{ALGORITHM FOR OPTIMIZATION OF MATERIAL FLOW}

For every manufacturing company is on beginning of designing production facilities in one of the most important steps to deploy the workplace in way, that material flow between them is optimized, and therefore the cost and time for carrying materials and semi-finished products between sites, too. There are many methods by which machines can be deploy.

When a large number of production machines and equipment manufactured, in a variety of products would be very time-consuming manual counting, demanding and not always accurate. Therefore authors decided to tackle the issue by creating a computer program. The basic method of which authors based is the triangular method, which is very complex and using a computer it is accurate.

Necessary input data are the same as the triangle method:

- Plan of the production of parts: the planned volume of production (e.g. in pieces / year),

- Details of the technological process of production: what machines will be needed for manufacturing all components, 
manufacturing process of each piece - operations, labor (in minutes) and the percentage of waste in each operation in the net weight in $\mathrm{kg} / \mathrm{pc}$.

- Layout: either the company needs to deploy into existing workplaces hall, or thus the calculation must be borne in mind, or will build a production hall of deployment by the resulting calculated.

- Data to determine the time efficiency of the fund: the number of workdays over which will be produced, the length of the workday, shift pattern and the estimated time losses as a percentage.

The output of the triangular method is as follows:

- The size of the effective time of the fund,

- Capacitance calculation of the number of machines,

- The size of the transported amount of material between all machines,

- The resulting optimum allocation of machines.

Authors created an algorithm that can transform the input data to the desired output data. The algorithm consists of eight parts:

1. Enter data to create maps of where to place machines. (Figure 1)

2. Enter the data about the number of parts produced, their quantities and net weights. (Figure 2)

3. Enter the data about the number of production machines and their names. (Figure 3)

4. Enter the number of manufacturing operations data for each part, labor, and the percentage of waste in each operation. (Figure 4)

5. Enter the data needed to calculate the effective time of the fund. (Figure 5)

6. The algorithm calculates and displays how many machines the enterprise will need. (Figure 5)

7. Algorithm which calculates and displays the quantities of material between all workplaces. (Figure 6)

8. At the end of the algorithm calculates and displays the resulting distribution of machines. (Figure 7)

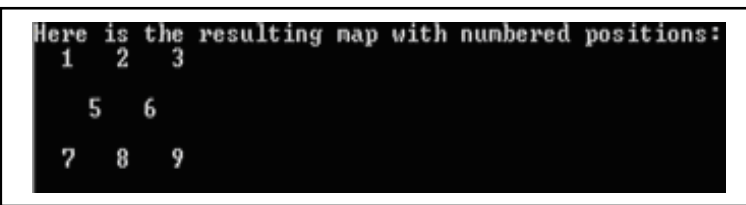

Fig. 1. Creating map in algorithm

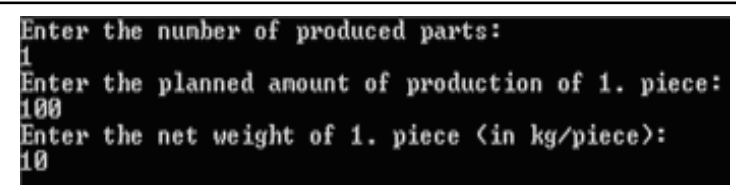

Fig. 2. Inserting information about produced parts

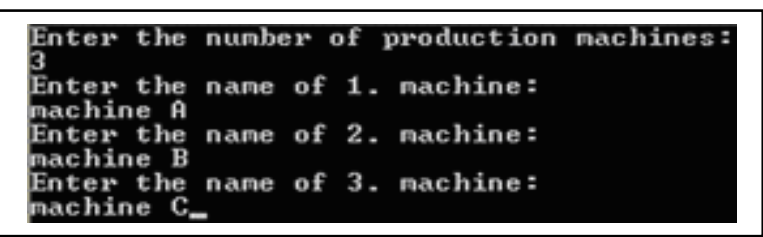

Fig. 3. Inserting information about machines

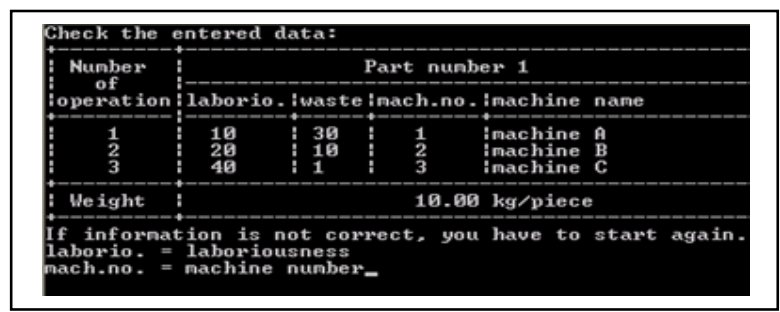

Fig. 4. Inserting manufacturing data

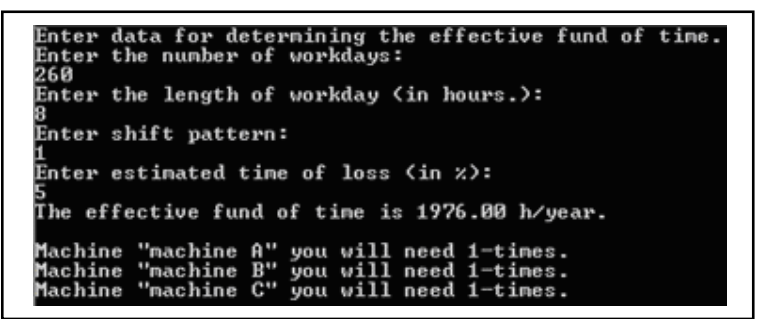

Fig. 5. Calculating the effective time and need of machines

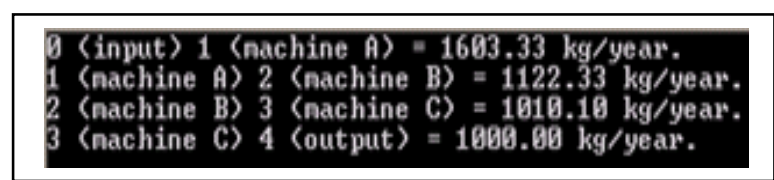

Fig. 6. Displaying the quantities of material flow

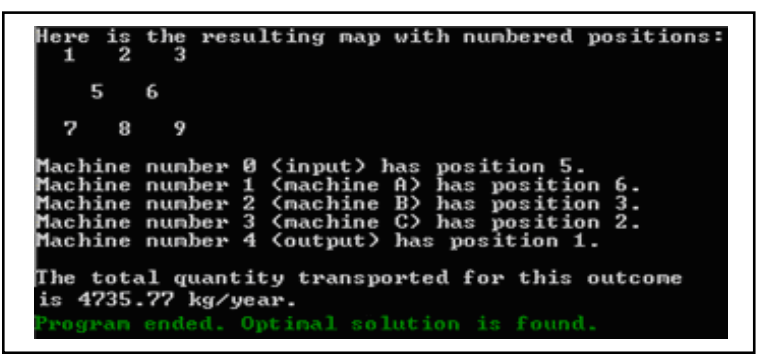

Fig. 7. Calculation and displaying results

\section{CONCLUSION}

The first advantage of the algorithm is that checks all possible combinations of place of work and find the best. Manual counting would be very lengthy, but the use of computer technology saves time and money. Other benefits of algorithm include the possibility of defining own network, or maps, in which workplaces will be placed. This provides the advantage that the calculated solution may not be transformed into a triangular network layout, but already it is in the layout. Authors see opportunity to extend algorithm with more functions and made a computer program with user friendly environment. Then the program will find its place in practice an help enterprises improve their material flow and cut reduce costs.

\section{ACKNOWLEDGEMENTS}

Authors thank to Faculty of Materials Science and Technology in Trnava, Slovak University of Technology in Bratislava and people from Institute of Industrial Engineering, Management and Quality for their support and help. Authors thanks namely to associate professor Rybanský, associate professor Čambál, associate professor Cagáňová and Ing. Drahňovský, PhD. This paper is result of private project.

\section{REFERENCES}

Leščišin, M.; Stern, J.; Dupal', A. (1998). Production management I. Vydavatel'stvo Ekonóm, ISBN 80-2250911-6, Ekonomická univerzita v Bratislave

Leščišin, M.; Stern, J.; Dupal', A. (1998). Production management II. Vydavatel'stvo Ekonóm, ISBN 80-8057452-9, Ekonomická univerzita v Bratislave

Rybanský, R (2005). Production management - instructions for exercises, STU, ISBN $80-227-2190-5$, Bratislava

Rybanský, R.; Drahňovský, J. (2009). Production management I. STU, ISBN 978-80-8096-084-1, Bratislava

Rybanský, R.; Drahňovský, J. (2009). Production management II. STU, ISBN 978-80-8096-085-8, Bratislava

*** (2010) http://web.tuke.sk/sjf-kbiaam/zbornik/09.pdf

Methodology for the selection of simulator, Accessed on: 2009 03-02 